\title{
POR la REAGREDITAGIÓN
}

Juan Carlos González

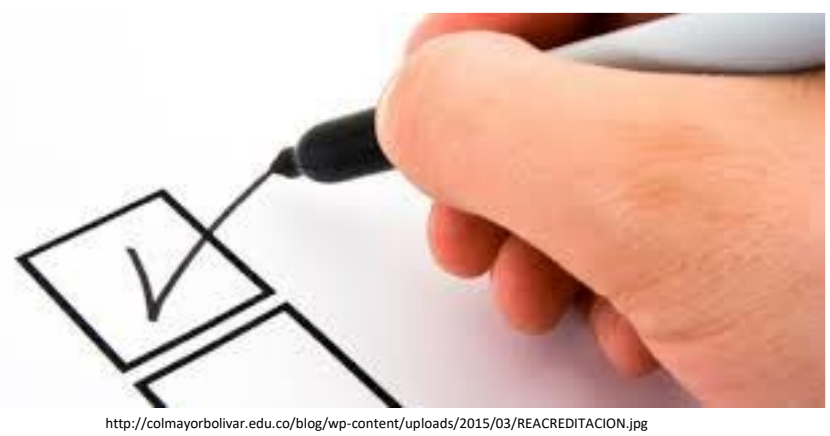

En 2017 la Fundación Universitaria Juan N Corpas deberá reacreditarse. Para esto la rectoría dispuso una vez más al doctor Guillermo Restrepo Ch. como cabeza para llevar a cabo el proceso de autoevaluación pertinente y organizar la documentación que se debe enviar a la entidad correspondiente.

He visto el inmenso esfuerzo del profesor Restrepo y reconozco que me asombra ver esa vitalidad y fuerza con que ha asumido el reto. A ratos siento que le faltan recursos, pero veo que no desfallece y que literalmente le "mete el pecho".

Hace poco me reuní con él y le pregunté si ya había sistematizado toda la información que tiene. Me dijo que estaba en eso, pero que ya tiene claridad sobre los aspectos que debemos fortalecer, los cuales son:

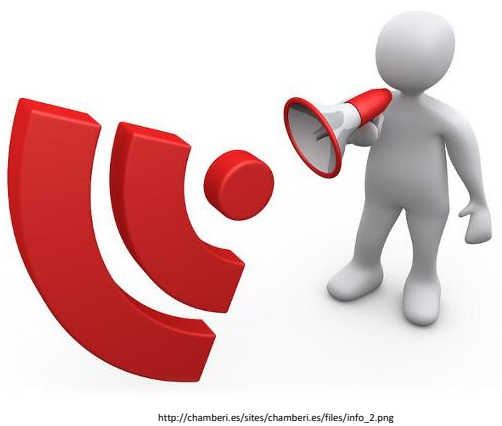

1. Debemos mejorar los procesos de información y comunicación. Si bien resulta evidente que estamos avanzando y que el programa KAWAK es un ejemplo, así como la página web y el funcionamiento de comités como el curricular, que muestran positivos avances, considera el doctor que la autoevaluación nos invita a seguir construyendo puentes que nos permitan saber lo que hacemos y cómo lo hacemos. Nos invita a continuar con aquellas reuniones que inició rectoría, donde se entrevista con cada docente y se cuentan los sueños y proyectos que están por implementar.

\footnotetext{
‡ MD. Especialista Medicina Familiar Integral, MSP. Director Departamento de Medicina Comunitaria juan.gonzalez@juanncorpas.edu.co
} 
2. En la docencia se hace necesario fortalecer el trabajo interdisciplinario entre los distintos docentes. Se debe combatir que los docentes desconozcan lo que hacen sus pares $y$ es importante crear espacios para que compartan experiencias (especialmente pedagógicas) y, por, sobre todo, ofrecer una oportunidad a la continuidad de procesos para adquirir competencias transversales donde varios docentes participan. El comité curricular presidido por decanatura se ha propuesto esto (y lo está haciendo regularmente) y por eso se debe continuar. Pero, se hace importante que los docentes como rutina, se reúnan en más espacios, donde hablen de sus estudiantes y de cómo ayudarse a mejorar su formación (reuniones de área o

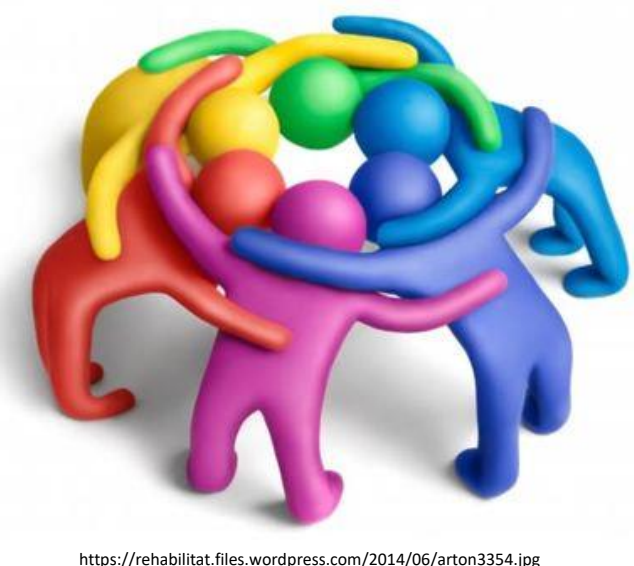
departamento).

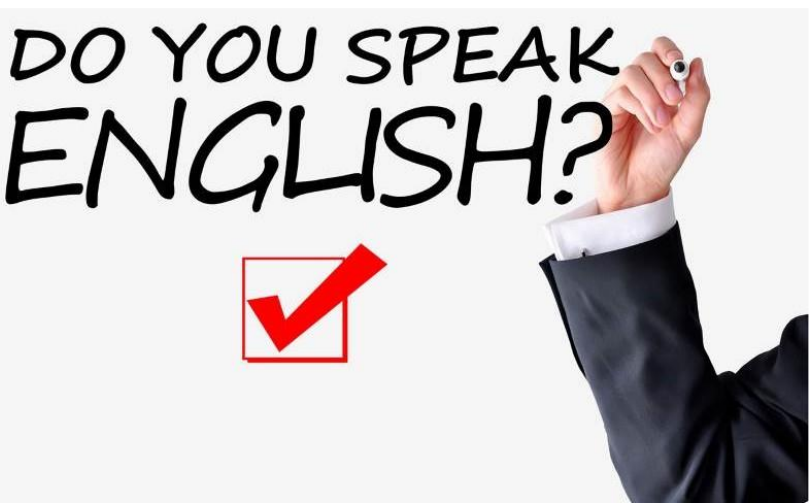

http://www.nativos.org/wp-content/uploads/2015/09/Do-you-Speak-English-blog-880x480.jpg
3. Se debe intensificar el aprendizaje del inglés por parte de los estudiantes y docentes; esto les abre un mundo de oportunidades. Son evidentes los logros. El nivel está subiendo y debemos reconocer que buena parte de nuestros estudiantes ingresan con habilidades mínimas. El centro de idiomas ha desarrollado un programa que está dando frutos. No se debe decaer, al contrario, se debe estimular, pues con ello, se les abre muchas oportunidades a nuestros estudiantes $y$, por, sobre todo, nos permite proyectar aún más a nuestra universidad.

4. Se debe vigorizar el proceso de admisiones. Se hace evidente que existe un número importante de estudiantes que no tienen la preparación que quisiéramos. Si se decide recibirlos, entonces se debe hacer un plan para nivelarlos. Si no, entonces precisar mejor el perfil de estudiantes que queremos tener para así producir el médico que anhelamos. En ello, debemos estimular esa sensibilidad con la que ingresan todos, pues claramente eso los hará mejores estudiantes $y$, por supuesto, que médicos cuando egresen.

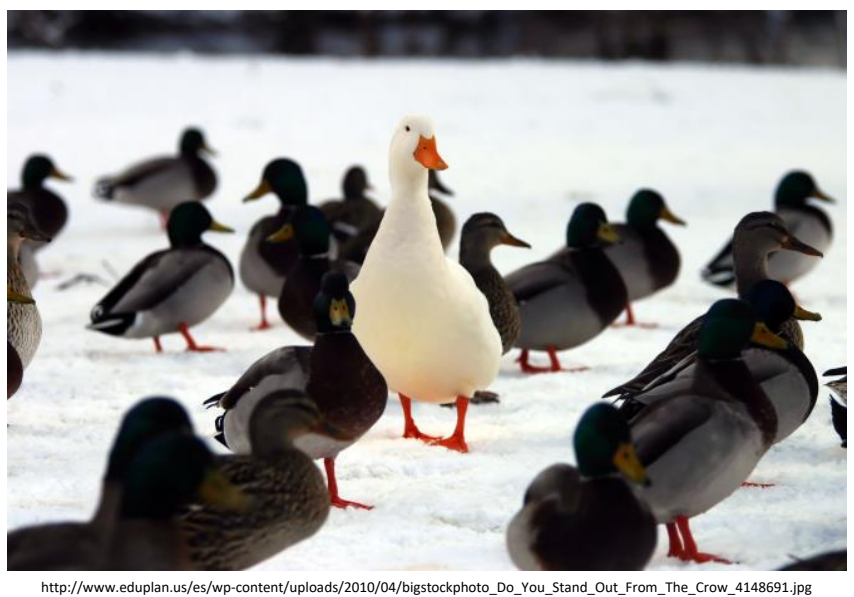




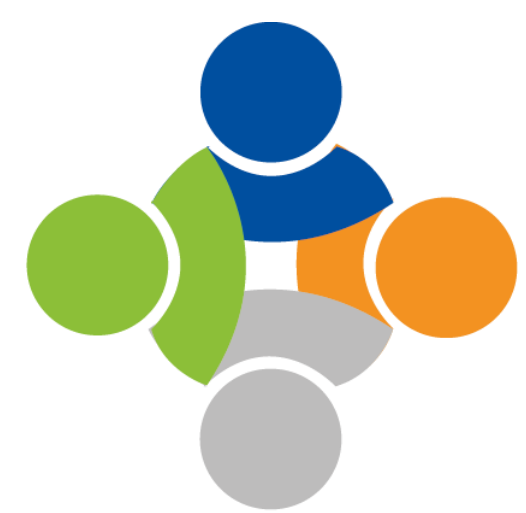

\section{GRUPOS DE INVESTIGACIÓN}

En investigación, resulta evidente el gran progreso. La Universidad ha estimulado al Centro de Investigaciones y este ha respondido. Ahora se hace necesario impulsar a todos nuestros docentes a que se comprometan con el mundo de la investigación. Así, con el ejemplo de los docentes, se dará el ejemplo a los estudiantes y así se estimularán los semilleros. Escribir y publicar se hacen imperativos, máxime cuando nosotros como universidad tenemos mucho que decir; por ejemplo, en lo social. Por lo mismo se deben promover y fortalecer las revistas y espacios para publicar. Reactivar a Medicor como centro de publicación es un propósito que se está desarrollando con fuerza y que debemos sostener y mantener. La Biblioteca se ha comprometido con hacer visible lo que producimos, mostrándonos caminos que debemos recorrer y que unidos sin duda lograremos establecer.

5. Relaciones internacionales. Reconociendo que se viene avanzando en este aspecto y que la Universidad ha hecho esfuerzos grandes, por ejemplo, con Estados Unidos, se hace necesario fortalecer aún más. Se debe promover que los docentes se relacionen con otros de distintas partes del país y del mundo para impulsar intercambios y vínculos. La creación de la oficina de Iniciativas Globales es una respuesta a la cual todos debemos apostarle.

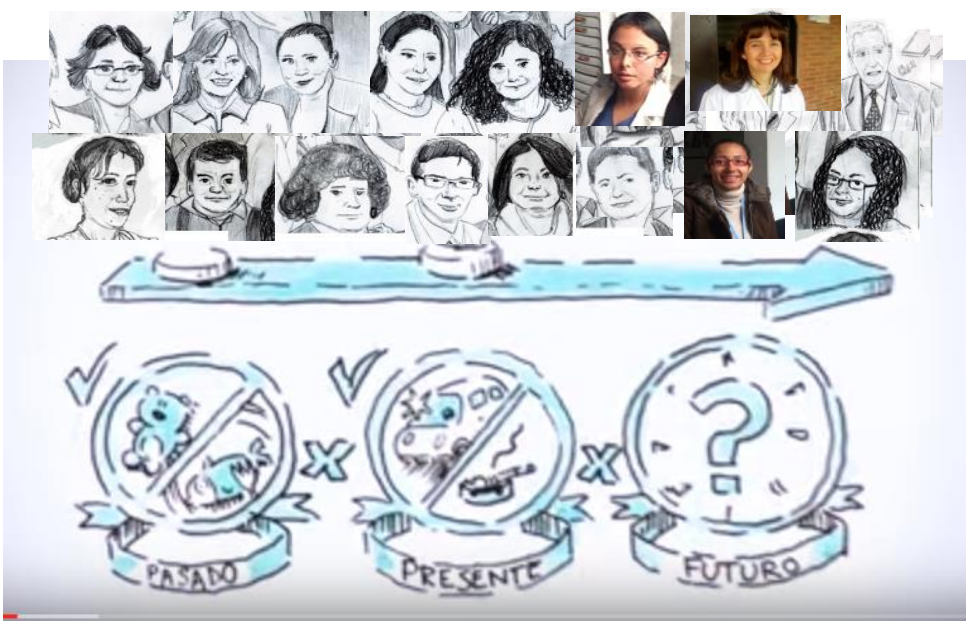

https://www.youtube.com/watch?v=TPACtJpx9MI

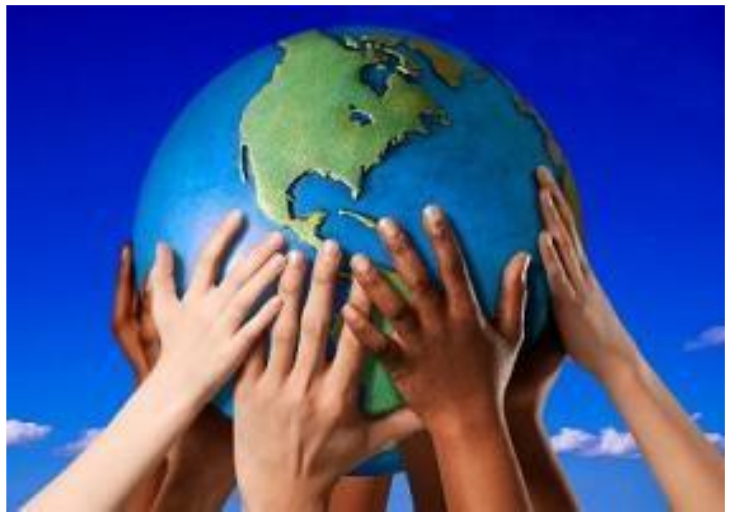

http://definicion de/wp-

content/uploads/2008/12/relacionesinternacionales.jpg

6. Fortalecer Medicina Comunitaria. Este departamento se ha visto sometido a cambios importantes, pero su filosofía hoy está más actual que nunca. Por ende, debe estimularse para que se reposicione y así convertirse en un ejemplo de cómo enseñar salud en la comunidad. Allí se sabe el cómo y el dónde. Ahora, a respaldarlos para que se conviertan otra vez en uno de los pilares de la reacreditación. 
7. Fortalecer los procesos de participación estudiantil y docente. Es increíble lo fácil que los estudiantes y los docentes expresan su sentir. No existe reunión efectuada por el comité de reacreditación donde no se perciba la libertad para expresarse. Sin embargo, se hace necesario desarrollar estrategias donde tal participación se vuelva la norma y, los mecanismos dispuestos para ello, entren a formar parte de la vida académica. Eso es lo que debemos construir.

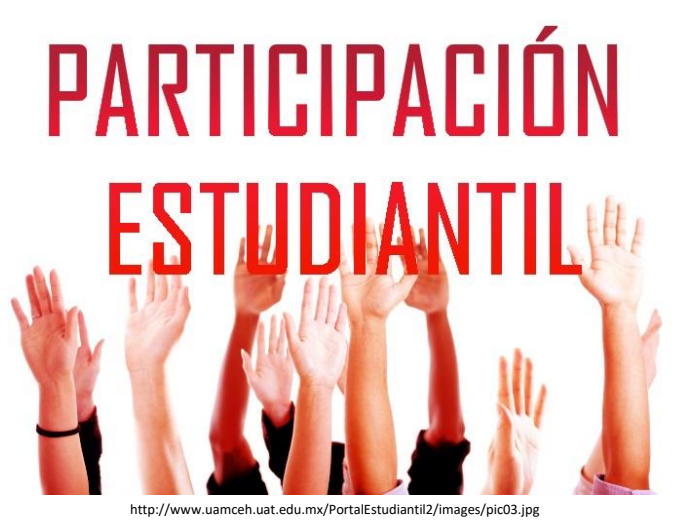

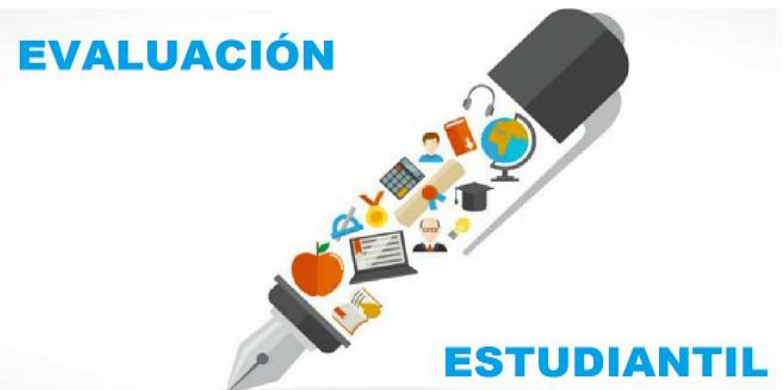

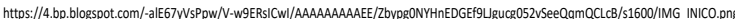

8. Homogenizar el sistema de evaluación estudiantil. Existe una inmensa variabilidad en las evaluaciones estudiantiles. Existen progresos en torno a pasar del simplista sistema de exámenes escrito al de evaluar por competencias sobre pacientes (reales o simulados). Ahí existe un progreso importante y de esfuerzo. Ahora debemos enseñar experiencias en tal sentido y buscar construir un modelo que nos acerque a alinear lo que enseñamos con lo que evaluarnos.

9. En torno a la infraestructura:

a. La biblioteca ha de concebirse como el núcleo de la vida académica. Mucho se ha progresado y resulta evidente cómo se han ido fortaleciendo las bases de datos y la aparición de repositorios donde todo lo que se produce quede allí registrado y de libre acceso. Pero, aún hace falta promover más mecanismos que fortalezcan su acceso por parte de estudiantes y docentes. Se debe convertir en un sitio donde toda la académica se encuentra, un sitio donde toda la académica recibe apoyo, un sitio donde todos nos sentimos bien.

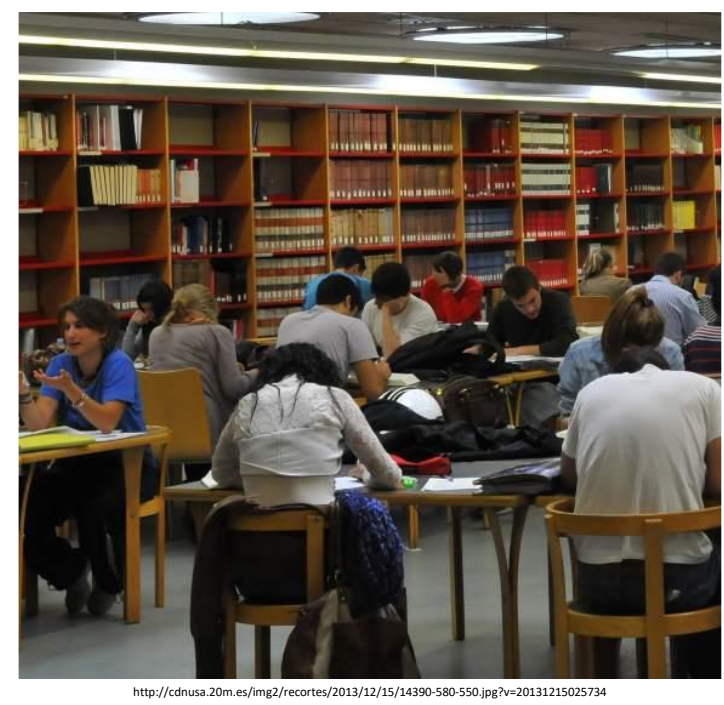




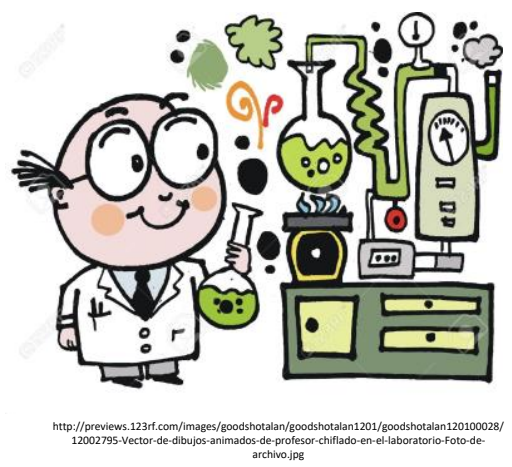

b. Laboratorios. Creemos que es necesario darles más apoyo. El mundo del laboratorio nos acerca al método científico en su expresión más "natural". Por eso, el poner en contacto al estudiante con el microscopio tiene un sentido, incluso simbólico, que debemos fortalecer. Asimismo, el mundo virtual y el mundo simulado. Donde los logros son evidentes, pero deben fortalecerse, pues es mucho lo que de allí surge como apoyo en los procesos pedagógicos. De igual forma, debemos montar "laboratorios sociales" donde de manera "controlada" pongamos en contacto al estudiante con la realidad social. En eso tenemos experiencia que se debe retomar. En tal sentido no se debe abandonar las ideas de esas casas comunitarias donde la población pueda contarle a nuestros estudiantes la realdad de cómo viven.

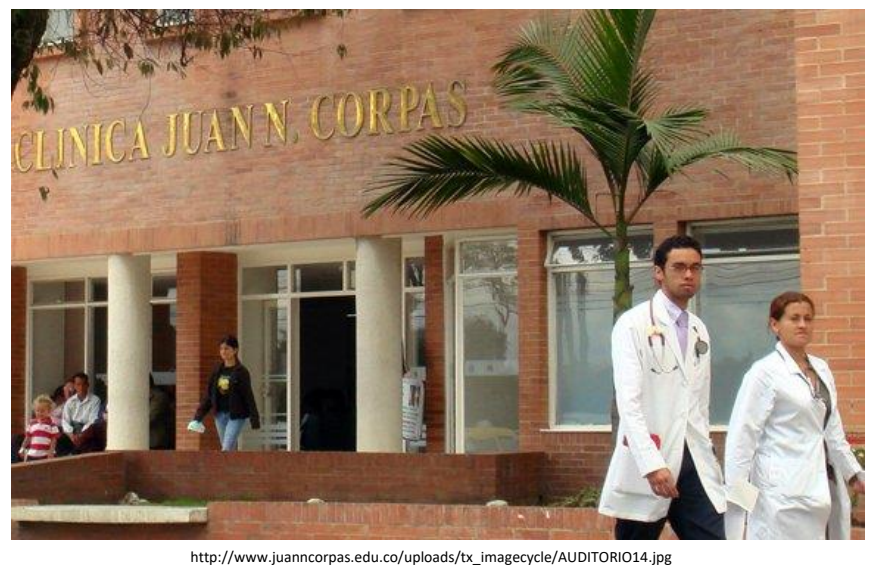

c. Fortalecer nuestra aula principal, la Clínica. La crisis del sector salud ha puesto en una situación delicada a nuestra clínica. Debemos fortalecerla otra vez con la academia. Construir un modelo de atención como el que se ha querido impulsar a través de la Medicina Familiar se hace necesario. Ya existen experiencias que muestran que es posible hacerlo. Debemos aprender de ellas y construir en menos de seis meses una que muestre el potencial de la Medicina Familiar Integral para atender y enseñar la Medicina.

Todo lo anterior tiene que estar consolidado al 30 de abril de 2017. En tal fecha se enviarán los documentos y seremos visitados por los pares en cualquier momento a partir de ese día. El doctor Restrepo considera que, con un poco de voluntad y esfuerzo, podemos tener lo descrito, listo para presentarlo. Yo le creo y estoy dispuesto a hacer lo que deba para asegurar esa reacreditación.

iCorpas vive!

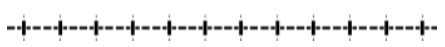

